\title{
How Small Polar Molecules Protect Membrane Systems against Osmotic Stress: The Urea-Water-Phospholipid System
}

\author{
Fátima O. Costa-Balogh, ${ }^{\dagger, *}$ Håkan Wennerström, ${ }^{\dagger}$ Lars Wadsö, ${ }^{\S}$ and Emma Sparr ${ }^{*, \dagger}$ \\ Physical Chemistry 1, Chemical Center, Lund University, P.O. Box 124, SE-22100 Lund, Sweden, Centro de \\ Estudos Farmacêuticos, Faculdade de Farmácia, Universidade de Coimbra, Coimbra codex P-3004-535, \\ Portugal, and Building Materials, Lund University, P.O. Box 118, S-221 00 Lund, Sweden
}

Received: May 26, 2006; In Final Form: September 6, 2006

\begin{abstract}
We investigate how a small polar molecule, urea, can act to protect a phospholipid bilayer system against osmotic stress. Osmotic stress can be caused by a dry environment, by freezing, or by exposure to aqueous systems with high osmotic pressure due to solutes like in saline water. A large number of organisms regularly experience osmotic stress, and it is a common response to produce small polar molecules intracellularly. We have selected a ternary system of urea-water-dimyristoyl phosphatidylcholine (DMPC) as a model to investigate the molecular mechanism behind this protective effect, in this case, of urea, and we put special emphasis on the applications of urea in skin care products. Using differential scanning calorimetry, X-ray diffraction, and sorption microbalance measurements, we studied the phase behavior of lipid systems exposed to an excess of solvent of varying compositions, as well as lipid systems exposed to water at reduced relative humidities. From this, we have arrived at a rather detailed thermodynamic characterization. The basic findings are as follows: (i) In excess solvent, the thermally induced lipid phase transitions are only marginally dependent on the urea content, with the exception being that the $\mathrm{P}_{\beta}$ phase is not observed in the presence of urea. (ii) For lipid systems with limited access to solvent, the phase behavior is basically determined by the amount (volume) of solvent irrespective of the urea content. (iii) The presence of urea has the effect of retaining the liquid crystalline phase at relative humidities down to $64 \%$ (at $27^{\circ} \mathrm{C}$ ), whereas, in the absence of urea, the transition to the gel phase occurs already at a relative humidity of $94 \%$. This demonstrates the protective effect of urea against osmotic stress. (iv) In skin care products, urea is referred to as a moisturizer, which we find slightly misleading as it replaces the water while keeping the physical properties unaltered. (v) In other systems, urea is known to weaken the hydrophobic interactions, while for the lipid system we find few signs of this loosening of the strong segregation into polar and apolar regions on addition of urea.
\end{abstract}

\section{Introduction}

In a living cell, there is a multitude of interactions between colloidal size components, such as nucleic acids, proteins, and membranes, that occur within the aqueous medium. The chemical potential of water, often expressed as the osmotic pressure, determines the precise magnitude of these interactions. In a properly functioning system, there is a fine balance between attraction/association and repulsion/dissociation. Thus, for complex organisms, the osmotic pressure is strongly regulated, and for humans, physiological saline (equivalent to $150 \mathrm{mM} \mathrm{NaCl}$ ) is the target value. This corresponds to air of $99.5 \%$ relative humidity (RH). For humans and higher animals, the skin serves to protect the individual from the osmotic stress of a dry environment. More primitive organisms have other means of protection/adaption to an osmotic stress. Typically, a change in the intracellular osmotic conditions first results in disturbances of metabolism and reproduction, whereas a large change in the osmotic pressure can lead to irreversible changes, followed by cell death. It is notable that general methods for food preservation are all based on creating a high osmotic pressure through drying, freezing, or adding salt or sugar.

* To whom correspondence should be addressed. Phone: +46 46222 4812. Fax: +46 46222 4413. E-mail address: emma.sparr@fkem1.lu.se.

$\dagger$ Physical Chemistry 1, Chemical Center, Lund University.

$\doteqdot$ Universidade de Coimbra.

$\S$ Building Materials, Lund University.
One generally applied strategy of protection against an osmotic stress is to introduce a small water-soluble component with low vapor pressure. The solute acts to reduce the chemical potential of the water, although it should preferably behave in a neutral way with respect to the functional components of the system. Plants exposed to regular night frosts can, for example, produce fructan for protection, 1,2 whereas some primitive animals use trehalose to survive the winter. ${ }^{3-5}$ Seaweed and marine alga can regulate the osmotic pressure of the saline water through the production of dimethyl sulfide. ${ }^{6,7}$ Polar solutes are also considered to protect the cell membranes in deep-sea elasmobranchs (sharks, skates, and rays) under conditions of high salinity, high pressure, and low temperature. The main solutes in the elasmobranch tissues are urea and methylamines, both of which are present at very high concentrations (up to $600 \mathrm{mM}^{8}$ ), and these are believed to affect the properties of the lipids. ${ }^{9}$

In higher animals, the organism is primarily protected from the osmotic stress caused by the dry air environment through the skin. The skin is our largest organ, and it has many vitally important functions. It serves as a permeability barrier, protecting the body from uncontrolled water loss and uptake of hazardous chemicals from the environment. The very outer layer of the skin is called the stratum corneum. It is only a few micrometers thick, but it still has a very important function in 
that it serves as the main barrier against diffusion through the skin. ${ }^{10}$ The stratum corneum is composed of flattened keratinfilled cells, the corneocytes, embedded in a matrix of stacked lipid bilayers in an array similar to that of "bricks and mortar", ${ }^{11,12}$ where the extracellular lipids constitute the only continuous regions and molecules passing the skin barrier must be transported through them. ${ }^{13,14}$ The stratum corneum extracellular lipids differ from most other biological membranes in that the lipid bilayers are primarily in a solid state at ambient relative humidities and temperatures, ${ }^{15}$ and only a smaller fraction of the lipids are in a liquid crystalline state. ${ }^{16,17}$

Under ambient conditions, there is a large gradient in the water across the stratum corneum. On the outside, the lipids are highly dehydrated when exposed to the dry air. It is well established that such dehydration can induce a shift in the lipids from the liquid crystalline to the solid state, ${ }^{18-20}$ which also has a strong effect on, e.g., the permeability. ${ }^{21}$ In the skin, the natural moisturizing factor (NMF) is an important component in protecting the skin from severe drying. ${ }^{22,23}$ The NMF is a complex mixture of low molecular weight water-soluble compounds that primarily consist of amino acids, urea, glycerol, lactate, citrate, sugars, and inorganic salts. ${ }^{24-26}$ There is a striking correlation between the absence of the NMF and states with stratum corneum abnormality. The NMF is virtually absent in psoriasis, ${ }^{27}$ in ichthyosis vulgaris, ${ }^{28}$ and in atopic dermatitis, ${ }^{29}$ one of the most common chronic inflammatory skin diseases characterized by dry and itchy skin. Furthermore, some of these small water-soluble compounds, such as urea and lactate, are commonly used in the medical treatment of dry skin, ${ }^{30,31}$ and the so-called moisturizers, such as urea (also known as carbamide), glycerol, and lactate, are main components of commercial skin lotions. Considering their molecular similarity with naturally occurring osmolytes, the hypothesis that the functional role of the "moisturizers" in the lotions is to compensate for the low water chemical potential in the outer layers of the stratum corneum appears to be reasonable.

In the present study, we aim to understand the effects of osmolytes on lipid lamellar systems through a thermodynamic characterization, particularly under conditions when the lipid system is under osmotic stress. We focus on the factors controlling the solid to liquid phase transition, which is the relevant feature for skin systems. As a model, we have chosen the ternary system of urea-water-dimyristoyl phosphatidylcholine (DMPC). By combining a number of experimental techniques, including differential scanning calorimetry (DSC), sorption microbalance measurements, small-angle X-ray scattering (SAXS), and wide-angle X-ray scattering (WAXS), the structure and the phase transitions have been characterized at low water content and in excess solution.

\section{Materials and Methods}

Materials. DMPC (1,2-dimyristoyl-sn-glycero-3-phosphatadylcholine, $>98 \%$ pure, $\left.M_{\mathrm{w}}=678 \mathrm{~g} / \mathrm{mol}\right)$ was obtained from Larodan AB (Malmö, Sweden) in powder form. Urea $\left(M_{\mathrm{w}}=\right.$ $60.06 \mathrm{~g} / \mathrm{mol}$ ) was obtained from Fluka Chemie $\mathrm{GmbH}$ (Buchs, Germany).

Sample Preparation. For the DSC, SAXS, and WAXS studies, samples were prepared as follows. Urea was dissolved in Milli-Q water at concentrations ranging from 1 to $40 \mathrm{wt} \%$ urea. The lipid samples were prepared by adding the aqueous urea solution to the dry lipids at the desired composition. The samples were centrifuged at $3500 \mathrm{rpm}$ for $10 \mathrm{~min}$, then heated for $3 \mathrm{~min}$ at $40{ }^{\circ} \mathrm{C}$, and finally dispersed by vigorous vortexing for at least $3 \mathrm{~min}$. The samples were equilibrated for at least 1 week before use. For the sorption microbalance studies, dry samples were prepared from DMPC and urea. The amount of urea in the dry samples varied between 0 and $20 \mathrm{wt} \%$. Urea was added to the dry lipid, and the obtained mixtures were dissolved in chloroform/methanol (1:1). The solvent was evaporated under vacuum at room temperature, and then the samples were reduced to a fine powder in a mortar and submitted to further drying under vacuum. Lipid-urea samples were also equilibrated for 1 week at $27{ }^{\circ} \mathrm{C}$ in an exicator with controlled relative humidities $(\mathrm{RH}=65,70$, and $84 \%)$, using saturated salt solutions. ${ }^{32,33}$ These samples were then studied with SAXS and WAXS.

Differential Scanning Calorimetry (DSC). Two different pieces of equipment were used. A highly sensitive differential scanning calorimeter, MicroCal MC.2 (MicroCal Inc., Northampton, MA), equipped with two total-fill cells of $1.2 \mathrm{~mL}$, one for the reference and the other for the sample to be studied, was used for liquid samples in a temperature range from 10 to 40 ${ }^{\circ} \mathrm{C}$. The references and samples were degassed using a Nueva II stirrer (Thermolyne) before being transferred to the cells, using a Hamilton syringe. The scan rate used was $30^{\circ} \mathrm{C} / \mathrm{h}$. Data were analyzed after subtraction of the baseline values obtained by scanning with the corresponding reference solutions in both the sample and reference cells. For samples with lower water content, experiments were performed in a $\mathrm{N}_{2}$ atmosphere using a DSC220 differential scanning calorimeter (Seiko Instruments) in the temperature range from 15 to $35^{\circ} \mathrm{C}$. The scan rate used was $30{ }^{\circ} \mathrm{C} / \mathrm{h}$. Samples with masses from 3 to $8 \mathrm{mg}$ were put into aluminum pans, which were then sealed. The reference used was a sealed empty aluminum capsule.

Small-Angle X-ray Scattering (SAXS). The measurements were performed on a Kratky compact small-angle system equipped with a position-sensitive detector (OED $50 \mathrm{M}$; M. Braun, Graz, Austria) containing 1024 channels with $53.0 \mu \mathrm{m}$ width. $\mathrm{Cu} \mathrm{K} \alpha$ radiation of wavelength $1.542 \AA$ was provided by a Seifert ID300 X-ray generator operating at $55 \mathrm{kV}$ and 40 mA. A $10 \mu \mathrm{m}$ thick nickel filter was used to remove the $\mathrm{K} \beta$ radiation, and a $1.55 \mathrm{~mm}$ tungsten filter was used to protect the detector from the primary beam. The sample-to-detector distance was $277 \mathrm{~mm}$. The volume between the sample and the detector was kept under vacuum during data collection in order to minimize the background scattering. Samples were measured in a sample holder with mica windows, and the temperature was varied between 18 and $30^{\circ} \mathrm{C}$. The temperatures were kept constant at each value $\left( \pm 0.1^{\circ} \mathrm{C}\right)$ with a Peltier element.

Wide-Angle X-ray Scattering (WAXS). Experiments were performed with the same samples and equipment (SWAXS equipment) used for SAXS measurements, using two detectors (1024 and 1024 channels) and the same temperature ranges.

Sorption Measurements. A DVS Advantage sorption balance (Surface Measurement Systems Ltd., London, U.K.) was used to study the sorption isotherms. This technique uses a small sample $(4-6 \mathrm{mg})$, which is placed in a glass cup and exposed to a stream of $\mathrm{N}_{2}$ with a programmed relative humidity. The sample was first dried in dry $\mathrm{N}_{2}$ for $4 \mathrm{~h}$ and then exposed to an $\mathrm{RH}$ ramp from 0 to $98 \%$ for $46 \mathrm{~h}$. The sorption was continuously determined by weighing the sample with a microbalance.

\section{Results and Discussion}

DMPC Phase Behavior in an Excess of Urea-Water Solutions. We have investigated how DMPC lamellar phases respond to the changing urea content of an excess aqueous solution. The excess solution acts as a reservoir and determines the chemical potential of water and urea in the lipid phase. 


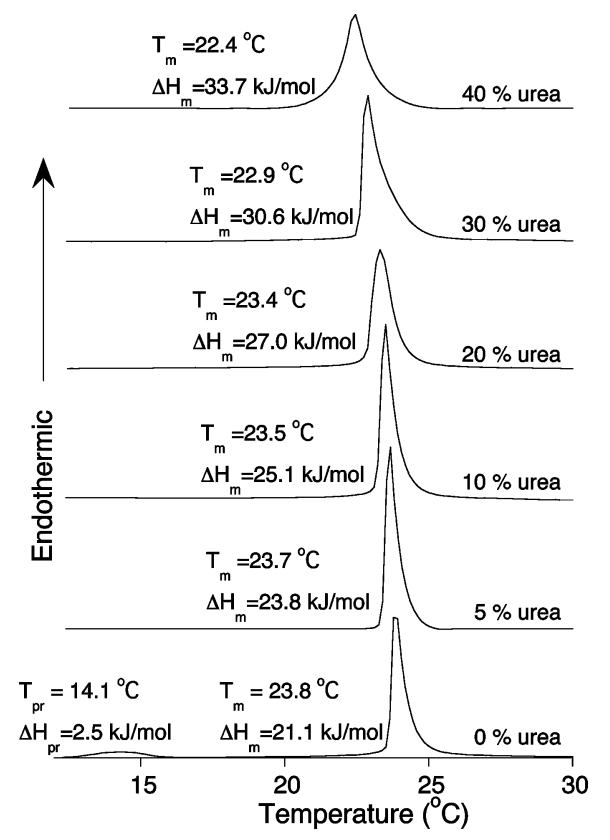

Figure 1. DSC heating thermograms for DMPC in excess solutions of urea and water with the compositions of $0,5,10,20,30$, and $40 \mathrm{wt}$ $\%$ urea. The thermograms show the phase transitions from the $\mathrm{L}_{\beta}$ phase to the $\mathrm{P}_{\beta}$ phase at $T_{\mathrm{pr}}$ and from the $\mathrm{P}_{\beta}$ phase (0\% urea) or $\mathrm{L}_{\beta}$ phase (5-40 wt \% urea) to the lamellar liquid crystalline $\mathrm{L}_{\alpha}$ phase at $T_{\mathrm{m}}$. Transition temperatures and transition enthalpies are shown.

Figure 1 shows the DSC heating curves of DMPC dispersions in excess solution with increasing amounts of urea $(0-40 \mathrm{wt}$
$\%$ urea). Fully hydrated DMPC bilayers in pure water exhibit two endothermic transitions on heating, a lower-temperature, lower-enthalpy pretransition $\left(T_{\mathrm{pr}}\right)$ at $14{ }^{\circ} \mathrm{C}$ and a highertemperature, higher-enthalpy main transition $\left(T_{\mathrm{m}}\right)$ at $23.8^{\circ} \mathrm{C}$. The pretransition arises from the conversion of a planar lamellar gel $\left(\mathrm{L}_{\beta}\right)$ phase to the rippled gel $\left(\mathrm{P}_{\beta}\right)$ phase, and the main transition, from the chain melting associated with the conversion of the $\mathrm{P}_{\beta}$ gel phase to the lamellar liquid crystalline $\left(\mathrm{L}_{\alpha}\right)$ phase. These are in good agreement with published values. ${ }^{34}$ When urea is added to the samples, the chain melting takes place at slightly lower temperatures, with the lowest temperature being that detected for DMPC in solution containing $40 \mathrm{wt} \%$ urea (Figure 1). It is a significant observation that there is only a slight broadening of the peaks when urea is added. Based on the Gibbs phase rule, one expects that, with two components in the solution, temperature regions where the two lipid phases, $\mathrm{L}_{\beta}$ and $\mathrm{L}_{\alpha}$, coexist with the excess water-urea solution should be observed. The data indicate that these regions are only $1-2$ ${ }^{\circ} \mathrm{C}$ wide. Finally, the pretransition is not detected, indicating that the rippled $\mathrm{P}_{\beta}$ phase is already destabilized at low urea concentrations.

The lipid structure was further characterized using SAXS and WAXS. The SAXS data demonstrate lamellar structures both above and below $T_{\mathrm{m}}$ (Figure $2 \mathrm{~A}$ and $\mathrm{B}$ ). At larger diffraction angles (WAXS), a prominent $4.12 \AA$ reflection, typical of gelstate hexagonally packed acyl chains, shows up in all samples at temperatures below $T_{\mathrm{m}}$, but no indication of the gel phase is detected for any of the samples at temperatures above $T_{\mathrm{m}}$. Representative WAXS spectra are shown in Figure 2C and D.
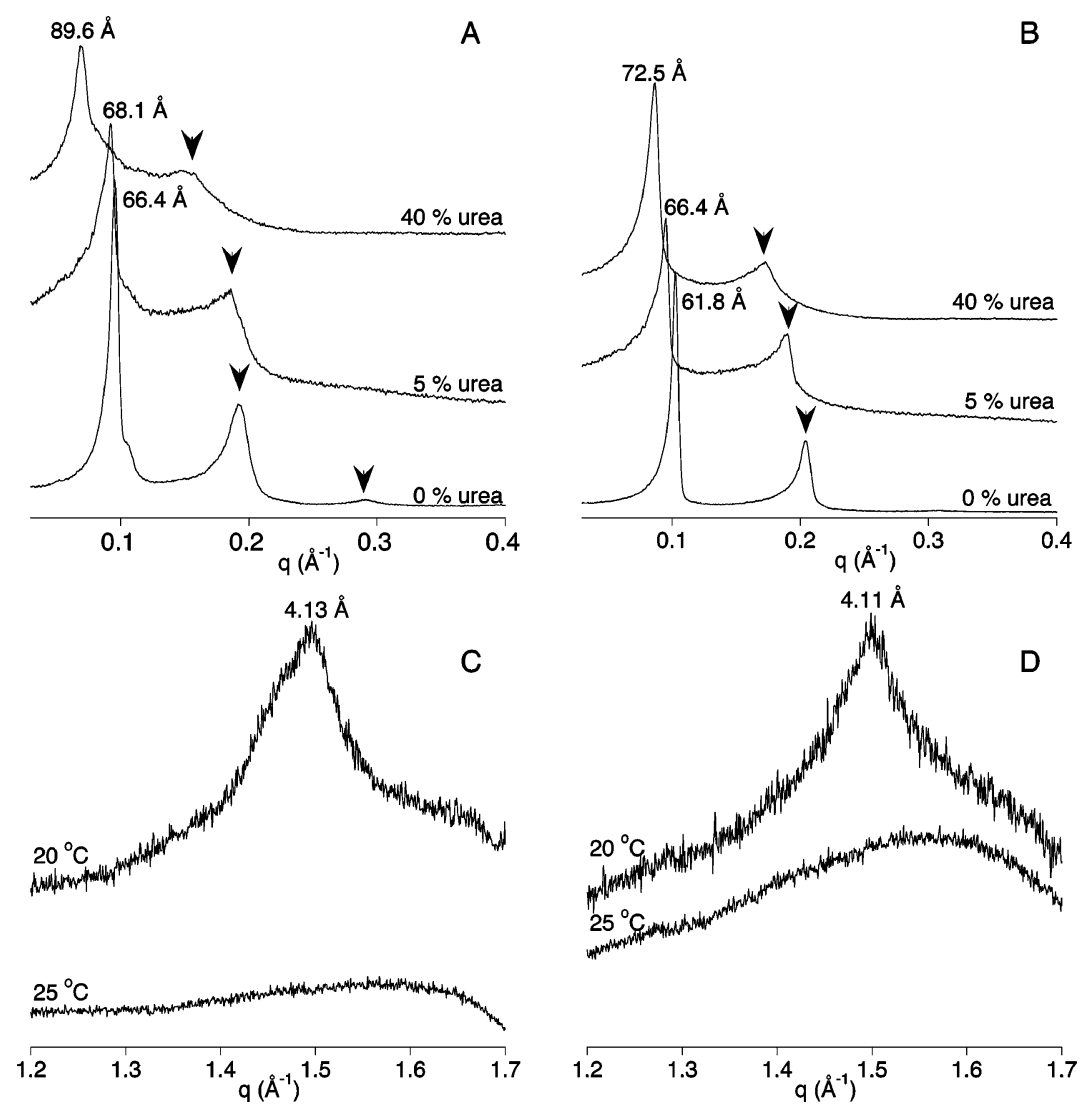

Figure 2. SAXS and WAXS diffraction patterns for DMPC-urea-water samples at temperatures above and below the main transition temperature $\left(T_{\mathrm{m}}\right)$. (A and B) SAXS profiles for DMPC in excess solutions of urea and water with compositions of 0,5 , and $40 \mathrm{wt} \%$ urea at (A) $20{ }^{\circ} \mathrm{C}$ and (B) $25^{\circ} \mathrm{C}$. Arrows indicate the second and third order of diffraction peaks from the lamellar phases. (C and D) WAXS profiles for DMPC at 20 and $25^{\circ} \mathrm{C}$ for (C) DMPC in excess water and (D) DMPC in the excess urea-water solution with $40 \mathrm{wt} \%$ urea. The peak at $\sim 4.12 \AA$, which is typical of gel-state hexagonally packed acyl chains, is present at temperatures below $T_{\mathrm{m}}$ at all urea concentrations, meaning that the gel phase is also stable in the presence of urea. 
TABLE 1: Summary of the DSC Data for DMPC Samples with Limited Access to the Solvent, ${ }^{a}$ Showing the Temperature Interval for the Two-Phase $\left(\mathbf{L}_{\beta}-\mathbf{L}_{\alpha}\right)$ Region at Varying Concentrations of Urea in the Solution

\begin{tabular}{cc}
\hline urea $($ wt $\%)$ & $\mathrm{L}_{\beta}-\mathrm{L}_{\alpha}$ region $\left({ }^{\circ} \mathrm{C}\right)$ \\
\hline 0 & $25.9-32.2$ \\
5 & $25.0-32.2$ \\
10 & $26.6-29.8$ \\
20 & $25.6-27.9$ \\
30 & $25.5-27.9$ \\
40 & $25.4-28.6$
\end{tabular}

a $80 \mathrm{wt} \%$ DMPC, $20 \mathrm{wt} \%$ solvent (urea and water).

This directly demonstrates that the lamellar gel phase is stable at $T<T_{\mathrm{m}}$ also in the presence of urea and that the lipids form a lamellar phase with fluid chains at higher temperatures.

Similar conclusions were drawn for the situations where the urea-water solution is not present in excess. The $\mathrm{L}_{\beta}$ and $\mathrm{L}_{\alpha}$ phases are both stable in the presence of urea at temperatures below and above the main transition temperature, respectively, as shown by SAXS and WAXS (not shown). The $\mathrm{P}_{\beta}$ phase is not present in the binary DMPC-water system at low water contents, ${ }^{34,35}$ and the pretransition is absent in all DSC scans. The DSC data show that the chain-melting transition from the $\mathrm{L}_{\beta}$ phase to the $\mathrm{L}_{\alpha}$ phase occurs at slightly higher temperatures compared to those when the lipid is present in excess solution (Table 1), which is expected for this system. ${ }^{34,35}$ The DSC data also give information on the phase boundaries of the two-phase $\mathrm{L}_{\beta}-\mathrm{L}_{\alpha}$ regions, and the temperature intervals for this two-phase region at different urea and water contents are summarized in Table 1. It is shown that the $\mathrm{L}_{\alpha}$ phase is induced (the lower phase boundary) at approximately the same temperature for all urea concentrations. However, the temperature for which the whole sample is in the $\mathrm{L}_{\alpha}$ phase (the upper phase boundary) is lowered in the presence of urea.

The combination of the DSC, SAXS, and WAXS data shows that urea slightly stabilizes the $\mathrm{L}_{\alpha}$ phase over the $\mathrm{L}_{\beta}$ phase. The decrease in $T_{\mathrm{m}}$ implies that the effect of urea is not simply to dehydrate the samples through a decrease in water chemical potential $\left(\Delta \mu_{\mathrm{w}}\right)$ that would lead to an increase in $T_{\mathrm{m}}$, as is the case for, e.g., high molecular weight water-soluble polymers. ${ }^{36}$ It is, therefore, concluded that urea is present within the lamellar structure. Similarly, it has been shown that the addition of urea causes a slight decrease in the melting temperature for the gel$\mathrm{L}_{\alpha}$ transition of phosphatidyl ethanolamines (PE) in excess solution and that it also stabilizes the $\mathrm{L}_{\alpha}$ phase over the reversed hexagonal $\left(\mathrm{H}_{\mathrm{II}}\right)$ phase. ${ }^{37-39}$ One can also note that sugars and amines such as, e.g., trehalose and betaine show the reverse effect in phosphatidylcholine bilayers in that they cause an increase in the chain-melting temperature. ${ }^{40,41}$

The most striking observation in these data is that urea has such a small effect on the lipid phase behavior. The calorimetric and X-ray data show that the general phase behavior is barely affected by the addition of urea, although the positions of the phase boundaries are slightly shifted and a narrow two-phase region is induced. The only real exceptions to this are that the $\mathrm{P}_{\beta}$ phase is not stable in the presence of urea and that the chainmelting transition thus occurs between the $\mathrm{L}_{\beta}$ phase and the $\mathrm{L}_{\alpha}$ phase. We further conclude that the transition enthalpies for urea concentrations between 5 and $20 \%$ are comparable to the sum of the enthalpies for the pretransition and the main transition for pure DMPC (Figure 1). This, again, implies that urea has a very minor effect on the $\mathrm{L}_{\beta}-\mathrm{L}_{\alpha}$ phase transition in excess solution. It should also be noted that the calculated temperature for the (metastable) $\mathrm{L}_{\beta}-\mathrm{L}_{\alpha}$ phase transition of pure DMPC in

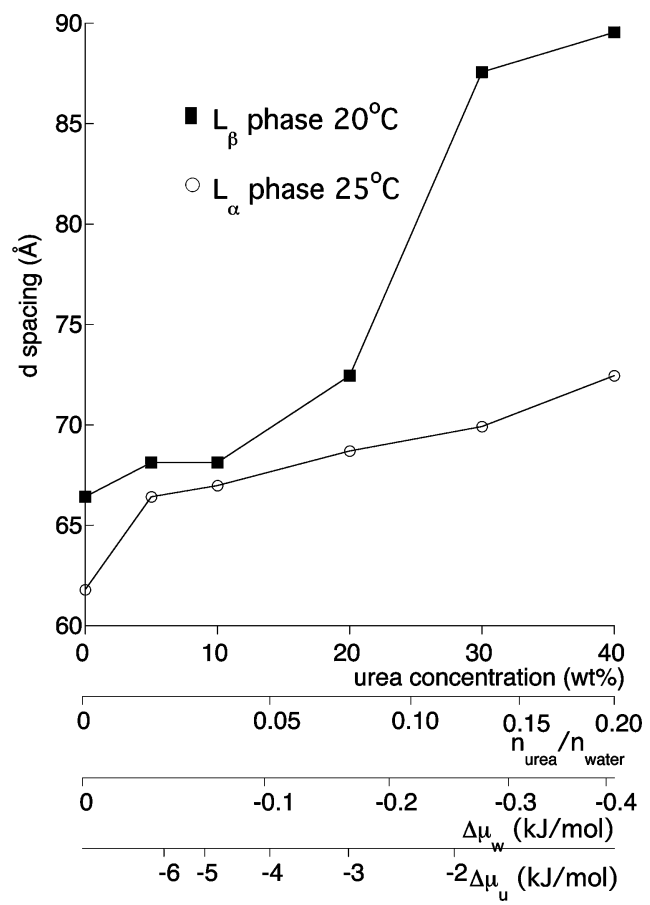

Figure 3. Variations in the lamellar repeat distance with the composition of the excess urea-water solution: $\mathrm{L}_{\beta}$ phase, $20{ }^{\circ} \mathrm{C}(\boldsymbol{\square})$ and $\mathrm{L}_{\alpha}$ phase, $25^{\circ} \mathrm{C}(\bigcirc)$. Corresponding values for the molar composition $\left(n_{\mathrm{u}} /\right.$ $\left.n_{\mathrm{w}}\right)$ and the chemical potentials of water $\left(\Delta \mu_{\mathrm{w}}\right)$ and urea $\left(\Delta \mu_{\mathrm{u}}\right)$ are also shown.

excess water lies $\sim 1.5^{\circ} \mathrm{C}$ below the main transition temperature for the $\mathrm{P}_{\beta}-\mathrm{L}_{\alpha}$ phase transition, ${ }^{42}$ which can contribute to the small decrease in $T_{\mathrm{m}}$ in the presence of urea.

Lamellar Repeat Distances. The SAXS data provide information on the repeat distance of the lamellar phases, and we used these data to make interpretations of the location of urea in the lipid phase. Figure 3 shows the variation in the lattice parameter for the fully swollen $\mathrm{L}_{\alpha}$ and gel phases in excess solution at different urea-water ratios. There is significant swelling of both phases, and the swelling is most pronounced for the $\mathrm{L}_{\beta}$ phase at high urea concentrations. Similar effects have also been observed for other phospholipids in urea-water solutions. ${ }^{37}$ In all of these studies, the lipid lamellar phase is in equilibrium with an excess solution of known composition. This implies that, at equilibrium, the chemical potentials of each component are also fixed in the lamellar phase, although the composition is not known. In general, urea partitions unevenly between the fully swollen lipid phase and the excess aqueous solution, which might explain the observed swelling of the lamellar phases in the presence of urea.

The lamellar repeat distances were also measured at lower water content. Unlike the situation described above where the lipids are present in an excess urea-water solution, we here consider the case where the solvent is only present in the lipid phase(s). Figure 4A shows the variation in the lattice parameter for the $\mathrm{L}_{\beta}\left(20^{\circ} \mathrm{C}\right)$ and the $\mathrm{L}_{\alpha}\left(25^{\circ} \mathrm{C}\right)$ phases where the amount of lipid is kept constant ( $80 \mathrm{wt} \%$ ) and the ratio between water and urea is varied. The lattice parameter is virtually independent of the urea-water ratio; thus, there are no significant changes in the area per lipid headgroup, which was found to be 53-54 $\AA^{2}$ in the $\mathrm{L}_{\alpha}$ phase and $47-48 \AA^{2}$ in the $\mathrm{L}_{\beta}$ phase for mixtures of 80 wt \% DMPC. In another set of experiments, we studied the swelling of the lamellar phases when urea was added in different amounts to a mixture of DMPC and water (80 wt \% DMPC, 20 wt $\%$ water; Figure 4B). The addition of urea causes an increase in the lattice parameter that corresponds very well 

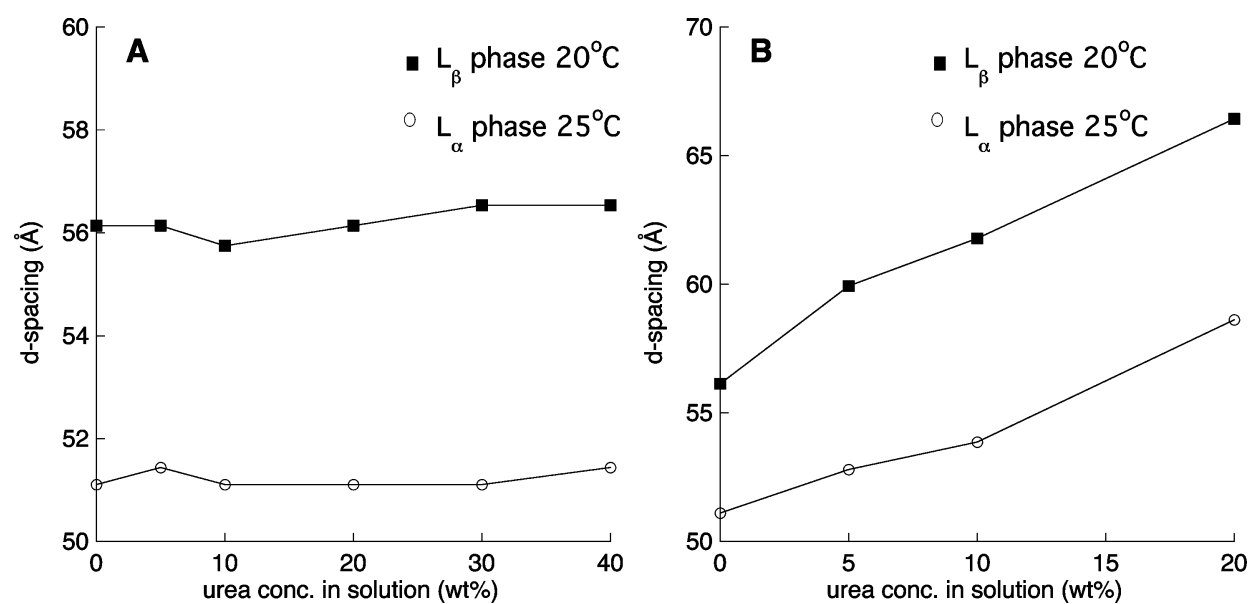

Figure 4. Variations in the lamellar repeat distance with the composition of the urea-water solutions in systems with limited access to the solvent: $\mathrm{L}_{\beta}$ phase, $20{ }^{\circ} \mathrm{C}(\mathbf{\square})$ and $\mathrm{L}_{\alpha}$ phase, $25{ }^{\circ} \mathrm{C}(\mathrm{O})$. (A) The effect of water replacement by urea: The composition of the water-urea solution was varied, and the lipid composition in all samples was kept at $80 \mathrm{wt} \%$ (i.e., $20 \mathrm{wt} \%$ water-urea solution). (B) The effect of urea addition to a lipid-water system: The composition of the water-urea solution was varied, and the lipid-water ratio remained the same in all samples. In the sample with no urea, the composition was $80 \mathrm{wt} \%$ lipid and $20 \mathrm{wt} \%$ water. Urea was then added in different proportions to this mixture.

to the expected increase due to the increase in volume by the added solute. From this, we conclude that the swelling behavior of the lamellar phases in urea-water is consistent with 1D swelling, meaning that the lipid bilayer thickness is constant and that all water and added urea goes to the polar layer separating the bilayers. This implies that urea is present in the aqueous layers and that it does not partition into the bilayer to any appreciable extent. We also stress that the urea-water mixture behaves ideally in the sense that urea replaces the water without affecting the packing properties and the headgroups of the lipids in the $\mathrm{L}_{\alpha}$ and $\mathrm{L}_{\beta}$ phases. This is also supported by the WAXS data obtained from the same samples, which show that the position of the peak corresponding to the gel-state hexagonally packed acyl chains remains unchanged at $\sim 4.12$ $\AA$ upon the addition of urea, implying that the area per lipid hydrocarbon chain remains unchanged when water is replaced by urea (assuming that the tilt angle of lipids in the bilayer is not altered). The lattice parameter and the calculated headgroup areas in the $\mathrm{L}_{\alpha}$ and $\mathrm{L}_{\beta}$ phases obtained for pure DMPC show good agreement with previous studies on the same system. ${ }^{43}$

DMPC Hydration in the Presence of Urea. To address the effect of urea on the lipid phase behavior under dehydration, we investigated lipid hydration at different urea concentrations by means of sorption microbalance measurements, where we measure the water uptake as a function of relative humidity. The sorption measurement provides a relationship between the water content and the water chemical potential $\left(\Delta \mu_{\mathrm{w}}\right)$, expressed in terms of the osmotic pressure $\left(\Pi_{\mathrm{osm}}\right)$, or the relative humidity $(\mathrm{RH}$, given in \%),

$$
\Delta \mu_{\mathrm{w}}=-V_{\mathrm{w}} \Pi_{\mathrm{osm}}=R T \ln (\mathrm{RH} / 100)
$$

The sorption processes in the ternary lipid-urea-water systems are rather complex as several different processes occur simultaneously. To enable a deeper analysis of the results, we will, therefore, first consider the binary lipid-water and ureawater systems.

The phase behaviors of the binary phospholipid-water systems have previously been studied both experimentally and theoretically. ${ }^{18,42,44}$ In a few cases, $T-\Delta \mu_{\mathrm{w}}$ phase diagrams for phospholipid-water systems have been established. ${ }^{35,45}$ One of the outcomes of these studies is that a first-order phase transformation from the $\mathrm{L}_{\beta}$ phase to the $\mathrm{L}_{\alpha}$ phase can be induced by an increase in the osmotic pressure of water, analogous to

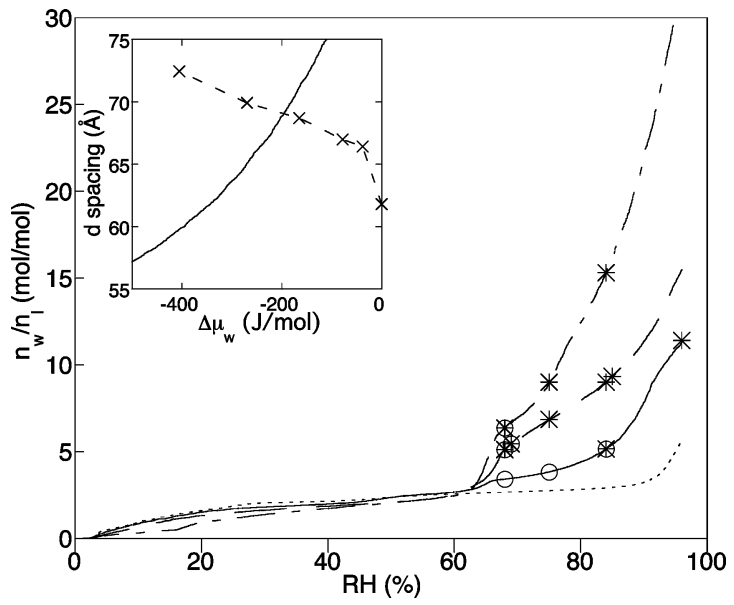

Figure 5. Sorption of water in the lipid-urea samples at $27^{\circ} \mathrm{C}$ : the number of moles of water per number of moles of lipid molecule $\left(n_{\mathrm{w}} /\right.$ $\left.n_{1}\right)$ as a function of relative humidity (RH). The composition of urea in the dry DMPC-urea samples was $0 \mathrm{wt} \%(---), 1 \mathrm{wt} \%(-), 10 \mathrm{wt}$ $\%(---)$, and 20 wt \% (- - - ). The phase behavior of some corresponding samples was determined by SAXS and WAXS: $\mathrm{L}_{\beta}$ phase (O) and $\mathrm{L}_{\alpha}$ phase $(*)$. Inset: Comparison between the sorption microbalance data (-) for the sample containing $20 \mathrm{wt} \%$ urea and the SAXS data (--) for the swelling of the $L_{\alpha}$ phase in excess solution: lattice parameter as a function of the chemical potential of water $\left(\Delta \mu_{\mathrm{w}}\right)$. From the sorption data, the lamellar repeat distance was calculated assuming 1D swelling and an area per lipid headgroup in the $\mathrm{L}_{\alpha}$ phase of $60 \AA^{2}{ }^{43} \Delta \mu_{\mathrm{w}}$ is directly related to $\mathrm{RH}$ (eq 1). For the samples used in the SAXS experiments, the $\Delta \mu_{\mathrm{w}}$ was obtained from the vapor pressure data $^{48}$ (compare to Figure 3 ), using the known composition values from the excess urea-water phase. At the intersection of the two curves, the compositions were determined to be $n_{\mathrm{w}} / n_{\mathrm{u}}$ $=9.2$ in the lamellar (lipid-water-urea) phase and $n_{\mathrm{w}} / n_{\mathrm{u}}=11.7$ in the excess water-urea solution. In other words, there was a slight partitioning of urea into the lipid lamellar phase compared to the aqueous solution. All experiments were performed at $27^{\circ} \mathrm{C}$.

the transition induced by an increase of temperature in excess water. This transition is observed as a stepwise increase in the sorption isotherm at $\mathrm{RH} \approx 94 \%$ at $27^{\circ} \mathrm{C}$. Ideally, the transition in the binary DMPC-water system should correspond to a vertical step in the sorption isotherm at constant relative humidity, ${ }^{45}$ and the deviation from the vertical slope in Figure 5 (dotted line) is most likely explained by kinetic delays in the experiment. At lower RH, the sorption isotherm shows only a 
moderate uptake of water over a large span in relative humidity. This reflects a minor swelling of the $\mathrm{L}_{\beta}$ phase.

The binary mixtures of urea and water have been extensively studied in the past. ${ }^{46-48}$ The vapor pressure over a saturated solution of urea in water is $74 \% \mathrm{RH}$ at $25^{\circ} \mathrm{C} .{ }^{48} \mathrm{In}$ terms of the sorption isotherm, this implies that urea does not absorb any significant amount of water at $\mathrm{RH}<74 \%$, while there is a sharp increase in water uptake at $\mathrm{RH}=74 \%$ to the saturation concentration, followed by a continuous uptake of water at higher RH due to dilution of the urea solution. With the same type of sorption measurements as used for DMPC, we determined the vapor pressure over a saturated urea solution to $76 \%$ $\mathrm{RH}$ at $27^{\circ} \mathrm{C}$ (data not shown).

When we consider the hydration of mixed lipid-urea samples, we can expect several (coupled) processes to occur, including lipid phase transitions, swelling of the lipid phases, urea dissolution, and dilution of the urea solution. Figure 5 shows the results for the uptake of water per phospholipid in the presence of urea at $27^{\circ} \mathrm{C}$. The sample composition is given as the percentage of urea relative to lipid in the dry samples. At the onset of the experiment, when the sample is in the fully dried state, we expect that solid lipids will coexist with solid urea and that these two components will compete for the water at low RH. The addition of urea has virtually no effect on the sorption behavior at $\mathrm{RH}<64 \%$. At these low relative humidities, urea is not dissolved, and the sorption curves simply reflect the swelling of the DMPC $\mathrm{L}_{\beta}$ phase by water. The dissolution of urea is detected as a sharp increase ( $>3$ waterurea) in the water uptake at $\mathrm{RH} \approx 64 \%$. The same feature is observed for all the samples that include urea, and we conclude that it involves the dissolution of urea into the lipid-water phase. The fact that this adsorption occurs at lower relative humidities compared to that of the pure urea-water system shows that the dissolution occurs in the lipid-containing phase. It should also be noted that, besides the dissolution of urea, the stepwise sorption at $\mathrm{RH} \approx 64 \%$ also involves a swelling of the lipid phase.

The presence of urea has a strong effect on the sorption behavior when $\mathrm{RH}>64 \%$, not only in that it causes increased swelling but also in that it significantly affects the position of the $\mathrm{L}_{\beta}-\mathrm{L}_{\alpha}$ phase transition. To enable the characterization of the lipid structure, the sorption data were combined with the results from SAXS and WAXS for lipid-urea samples that had been left to equilibrate at different RHs at $27{ }^{\circ} \mathrm{C}$. In addition, samples were also directly mixed to the desired composition determined from the microbalance data. Some results are shown in Figure 5, where the open circles refer to that a gel phase is detected in the sample, and the stars refer to the presence of a $\mathrm{L}_{\alpha}$ phase. At the lowest urea concentration (1\% in the dry sample), there is an increased swelling of the $\mathrm{L}_{\beta}$ phase, followed by an increase in water uptake at $87-93 \% \mathrm{RH}$ associated with the $\mathrm{L}_{\beta}-\mathrm{L}_{\alpha}$ phase transition, and finally, we see a continuous swelling of the $\mathrm{L}_{\alpha}$ phase. The isotherm looks qualitatively similar to that of pure DMPC, although the presence of a relatively small amount of urea causes a rather substantial shift of the phase transition toward lower relative humidities. This implies that urea has the ability to stabilize the liquid crystalline phase upon dehydration and to maintain the more fluid structure at low RH. This effect is even more pronounced at higher urea concentrations (10\% and $20 \%$ in the dry samples), where the phase transitions appear to coincide with the dissolution of urea at $\mathrm{RH} \approx 64 \%$. The transition is followed by a continuous swelling of the $\mathrm{L}_{\alpha}$ phase until the limit of full hydration, and thereafter, the fully swollen phase is equilibrating with an excess urea-water solution that is continuously diluted. From these data, it is clear that urea has the ability to protect the liquid crystalline phase upon dehydration and to prevent the formation of the solid gel phase. Similarly, disaccharides have been shown to stabilize the liquid crystalline bilayer over the solid gel state bilayer in dry lipid membranes. ${ }^{49,50}$

The sorption microbalance data (Figure 5) was combined with the SAXS data obtained for DMPC in excess solution (Figure 3). In this analysis, we take advantage of the fact that the chemical potentials of all the different components in the system are known. At equilibrium, the chemical potentials are equal in the fully swollen lamellar phase and in the excess aqueous solution for all of the components. The chemical potential of water $\left(\Delta \mu_{\mathrm{w}}\right)$ is obtained directly from the data on vapor pressure above the aqueous solution of urea from Scatchard et al. ${ }^{48}$ The chemical potential of urea $\left(\Delta \mu_{\mathrm{u}}\right)$ in the excess solution is obtained via the Gibbs-Duhem equation, which relates the changes in the chemical potentials of the different components at a fixed temperature, $n_{\mathrm{w}} \mathrm{d} \mu_{\mathrm{w}}+n_{\mathrm{u}} \mathrm{d} \mu_{\mathrm{u}}=0$, where $n$ is the number of moles of water $\left(n_{\mathrm{w}}\right)$ and urea $\left(n_{\mathrm{u}}\right)$, respectively. Finally, the chemical potential of the lipid $\left(\Delta \mu_{1}\right)$ in equilibrium with excess solution is $\Delta \mu_{1}=0$. To enable comparison with the data of the composition in the excess urea-water solution, the values of $\Delta \mu_{\mathrm{w}}$ and $\Delta \mu_{\mathrm{u}}$ at equilibrium are given in Figure 3 . We see that the sharpest increase in the lattice parameter is taking place at high urea concentrations, where $\Delta \mu_{\mathrm{w}}<-200$ $\mathrm{J} / \mathrm{mol}$ (corresponding to $\mathrm{RH}<90 \%$ ).

It is clear that the addition of urea causes a decrease in $\Delta \mu_{\mathrm{w}}$, as does the addition of any solute. The lattice parameters obtained from the SAXS experiments on the swelling of the $\mathrm{L}_{\alpha}$ phase in excess solution can be compared to the sorption isotherms that provide a relationship between $\Delta \mu_{\mathrm{w}}$ (via $\mathrm{RH}$ ) and the composition. As described above, this system exhibits 1D swelling, and it is, therefore, possible to directly estimate the thickness of each repeated unit in the lamellar phase from the sorption data. The calculated values from one of the sorption isotherms (20\% urea in the dry sample) are shown in the inset in Figure 5. From these calculations, it is possible to compare the actual composition in the lamellar phase (sorption data) with the composition of the excess solution (SAXS data) at the intersection of the curves. Based on these calculations, we find that urea shows a preferential partitioning into the lipid lamellar phase compared to the aqueous solution. This is consistent with the observation that urea readily dissolves at $64 \% \mathrm{RH}$ in the presence of lipids instead of at $74 \% \mathrm{RH}$ for pure water.

The Role of Urea in Lamellar Lipid Systems. By employing a number of different experimental techniques, we have characterized the ternary system of DMPC, urea, and water, and from the combination of the results, we obtained a molecular picture of how urea acts in the lipid bilayer systems. Urea is commonly used as a denaturant of proteins, as it weakens the hydrophobic interactions and, thereby, destabilizes the native structure at high concentrations. In surfactant solutions, the addition of urea can be used to increase the critical micelle concentration $(\mathrm{cmc})$ by the same mechanisms. ${ }^{51,52}$ However, the weakening of the hydrophobic interactions caused by urea is, by far, not sufficient to solubilize or disturb the phospholipid lamellar phases. This is demonstrated by the very minor effect on the overall lipid phase behavior and the observation that urea does not disturb the hexagonal packing of the acyl chains in the gel phase. Still, the destabilization of the $\mathrm{P}_{\beta}$ phase caused by the addition of urea shows that urea has a slight effect on the lipid bilayer system, probably associated with changes at the bilayer-water solution interface. 
The SAXS and sorption microbalance experiments provide quantitative data on the uptake of water and the lamellar repeat distance of the lamellar phases, and the combination of these data provides information on the lipid structure and the distribution of urea. In this analysis, we need to distinguish between the situation where urea has the choice of distributing between the aqueous and lipid layers in the lamellar phase (low water content) and the situation when the choice is between an excess water-urea solution and the lamellar phase (excess solution). In the former situation, the SAXS data show 1D swelling of both the $\mathrm{L}_{\alpha}$ and $\mathrm{L}_{\beta}$ phases in the urea-water mixtures. This clearly suggests that urea is present in the aqueous layer and that its effect on the lipid packing is very marginal. The situation is more complex when the lipids are present in an excess solution, and we observe an increase in swelling with an increase in the amount of urea in the solution (Figure 3 ). In general, urea should be unevenly distributed between the lipid phase and the excess aqueous solution. Urea is slightly surface active, and we can expect it to have a preference for the lipid phase compared to the aqueous solution. This is supported by the calculations made from the sorption microbalance data in Figure 5. The increase in urea concentration in the aqueous layers in the lamellar phase causes a decrease in $\Delta \mu_{\mathrm{w}}$, which, in turn, can lead to higher water uptake. This may explain the increase in the lamellar repeat distance, and, thus, the stronger repulsive interlamellar force, with the increase in urea concentration. However, a thorough analysis of the interlamellar forces in a two-component solution is rather complicated and it requires additional studies of the equilibrium phase behavior in response to variations in both $\Delta \mu_{\mathrm{w}}$ and $\Delta \mu_{\mathrm{u}}$.

A main conclusion in this study is that urea replaces water in the lipid lamellar system under dehydration in such a way that the properties of the lipid system remain largely unchanged. This is similar to the "water replacement hypothesis" for sugars in lipid membranes presented by Crowe et al. ${ }^{49,50}$ However, in this model, Crowe et al. stress a direct headgroup-solute interaction, whereas, in the case of urea, we propose an unspecific effect in that the properties of lipids appear neutral relative to the replacement of water with urea in the liquid phase. Urea is a polar substance with a low vapor pressure, and it can, therefore, act to maintain the liquid properties of the lipid system even at low RH. A consequence of this is that urea prevents the lipid phase transition upon dehydration, and thereby, it stabilizes the liquid crystalline phase. This is demonstrated both by the sorption microbalance data and also by the DSC studies performed in excess solution. To visualize this effect, we express the composition of the excess solution in terms of $\Delta \mu_{\mathrm{w}}$ and compare the present DSC results with data for the binary DMPC-water system (Figure 6). It is well-known that for many lipids, such as DMPC, a phase transition from the $\mathrm{L}_{\alpha}$ phase to a gel phase can be induced by dehydration. The decrease in $\Delta \mu_{\mathrm{w}}$ can be achieved by, e.g., decreasing $\mathrm{RH}$ or by letting the lipid system equilibrate with an excess aqueous solution that contains a water-soluble polymer that does not penetrate into the lipid system. ${ }^{36}$ In the present studies, DMPC was allowed to equilibrate with an excess solution where $\Delta \mu_{\mathrm{w}}$ was altered by the addition of urea. In this case, urea was also able to penetrate the lipid phase, and we monitored the lipid dehydration in the presence of urea. Thus, the data provide information on the effect of urea on the lipid phase behavior at different $\Delta \mu_{\mathrm{w}}$ values. With this perspective, it is obvious that the presence of urea has a rather dramatic effect on the lipid phase behavior under dehydration. Figure 6 shows the $T-\Delta \mu_{\mathrm{w}}$ phase diagram for DMPC, ${ }^{45}$ together with the data obtained from DSC in the

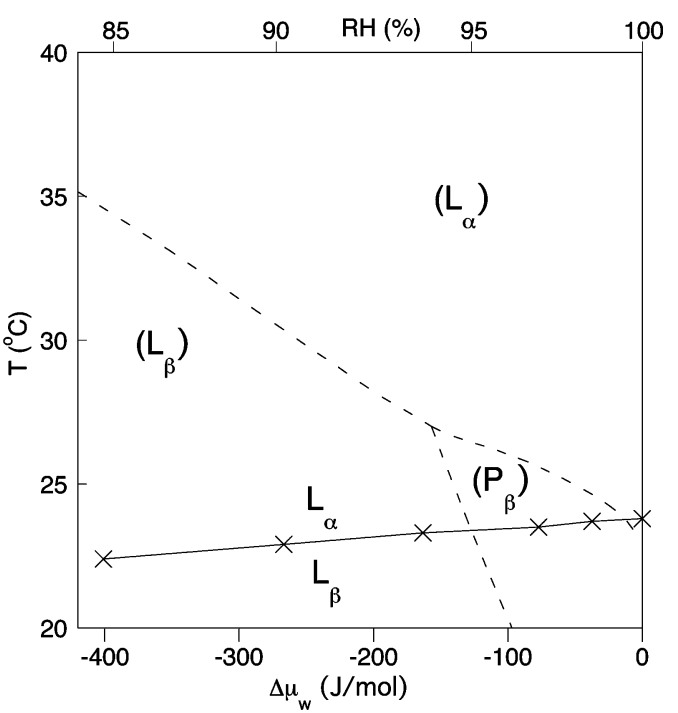

Figure 6. Phase diagram demonstrating how urea has the ability to stabilize the $\mathrm{L}_{\alpha}$ phase upon dehydration. Three phases $\left(\mathrm{L}_{\beta}, \mathrm{P}_{\beta}\right.$, and $\left.\mathrm{L}_{\alpha}\right)$ are present in the binary DMPC - water system (dashed lines and phases within parentheses), where a decrease in $\Delta \mu_{w}$ causes an increase in $T_{\mathrm{m}}$ (data from ref 45). The phase boundary for DMPC in the presence of urea at varying $\Delta \mu_{\mathrm{w}}$ values was determined from the DSC data (solid line and phases without parentheses; $\times$, measured points). It is shown that a decrease in $\Delta \mu_{\mathrm{w}}$ causes a slight decrease in $T_{\mathrm{m}}$. A decrease in $\Delta \mu_{\mathrm{w}}$ can be achieved by, e.g., decreasing RH.

excess urea-water solution. The values of $\Delta \mu_{\mathrm{w}}$ at the temperatures of the phase transition at different compositions of the ternary mixtures were calculated using the literature data on the vapor pressure at $25{ }^{\circ} \mathrm{C}$ (giving $\Delta \mu_{\mathrm{w}}$ at $25{ }^{\circ} \mathrm{C}$ ) ${ }^{48}$ and the heat capacities of urea-water solutions. ${ }^{46}$ The figure shows that the gel- $\mathrm{L}_{\alpha}$ transition temperature for pure DMPC in water increases when $\Delta \mu_{\mathrm{w}}$ decreases. When urea is present, the corresponding decrease in $\Delta \mu_{\mathrm{w}}$ is accompanied by a slight lowering of the transition temperature. This means that the $\mathrm{L}_{\alpha}$ phase is stable at temperatures far below the transition temperature of the binary system when the water chemical potential is reduced in the urea-containing lipid phase. This can have important implications in, e.g., the action of the NMF and skin care products in human skin at low and ambient $\mathrm{RH}$, and in the high amount of urea in deep-sea elasmobranches under conditions of high salinity, high pressure, and low temperature. Furthermore, this can be seen as a more general mechanism that is also applicable to other small water-soluble solutes with low vapor pressure, such as glycerol, betaine, and sugars, and it can explain the observation that glycerol decreases the chainmelting temperature for stratum corneum model lipids at low $\mathrm{RH}^{53,54}$

\section{Conclusions}

Osmotic stress caused by, e.g., drying or freezing can induce structural reorganization in macomolecular assemblies, such as the lipid bilayer systems in cell membranes or in the skin, which typically has severe consequences for their function. The addition of water-soluble solutes with low vapor pressure, such as urea, glycerol, betaine, and sugars, is one way to protect the systems from these effects, and this is widely exploited in nature and also in different technical applications. In this study, we explore the molecular mechanism by which such solutes affect lipid membranes. The model system chosen is a ternary system of urea, water, and a phosphatidylcholine (DMPC), and the following are our conclusions: 
(i) In excess solvent, the thermally induced lipid phase transitions are only marginally dependent on the urea content, with the exception that the $\mathrm{P}_{\beta}$ phase is not observed in the presence of urea.

(ii) For lipid systems with limited access to solvent, the phase behavior and structural parameters are basically determined by the amount (volume) of solvent irrespective of the urea content.

(iii) The presence of urea has the effect to retain the liquid crystalline phase at relative humidities down to $64 \%\left(27^{\circ} \mathrm{C}\right)$, whereas, in the absence of urea, the transition to the gel phase occurs already at a relative humidity of $94 \%$. This demonstrates the protective effect of urea against osmotic stress.

(iv) In skin lotions, urea is claimed to act as a moisturizer or humectant. We find this terminology to be slightly misleading in that urea has the effect of replacing the water while keeping the physical properties unaltered. This way, one can maintain the elastic properties of the skin also under dry conditions.

(v) Urea shows a slight preference for the lipid phase compared to the aqueous solution, which can lead to swelling of the lamellar phases in the excess urea-water solution.

(vi) In other systems, urea is known to weaken the hydrophobic interactions, while for the lipid system we find few signs of this loosening of the strong segregation into polar and apolar regions on addition of urea.

Acknowledgment. F.C.-B. acknowledges the "Fundação para a Ciência e para a Tecnologia, Portugal" for financial support (ref SFRH/BD/10306/2002), and E.S. acknowledges the Swedish Research Council (Vetenskapsrådet) for financial support. We thank Tommy Nylander for fruitful discussions and Vitaly Kocherbitov for help with the DSC measurements.

\section{References and Notes}

(1) Vereyken, I. J.; Chupin, V.; Islamov, A.; Kuklin, A.; Hincha, D. K.; de Kruijff, B. Biophys. J. 2003, 85, 3058-3065.

(2) Pontis, H. G. J. Plant Physiol. 1989, 134, 148-150

(3) Cacela, C.; Hincha, D. K. Biophys. J. 2006, 90, 2831-2842.

(4) Elbein, A. D.; Pan, Y. T.; Pastuszak, I.; Carroll, D. Glycobiology

2003, 13, 17R-27R.

(5) Crowe, J. H.; Hoekstra, F. A.; Crowe, L. M. Annu. Rev. Physiol. 1992, 54, 579-599.

(6) Vairavamurthy, A.; Andreae, M. O.; Iverson, R. L. Limnol. Oceanogr. 1985, 30, 59-70.

(7) Kirst, G. O. Annu. Rev. Plant Physiol. Plant Mol. Biol. 1990, 41, 21-53.

(8) Perlman, D. F.; Goldstein, L. In Physiology of Elasmobranch Fishes; Shuttleworth, T. J., Ed.; Springer-Verlag: New York, 1989; pp 253-273.

(9) Barton, K. N.; Buhr, M. M.; Ballantyne, J. S. Am. J. Physiol.: Regul., Integr. Comp. Physiol. 1999, 276, R397-R406.

(10) Elias, P. M. J. Controlled Release 1991, 15, 199-208

(11) Michaels, A. S.; Chandrasekaran, S. K.; Shaw, J. E. AIChE J. 1975 $21,985-996$.

(12) Elias, P. M. J. Invest. Dermatol. Suppl. 1983, 80, 44-49.

(13) Barry, B. W. Eur. J. Pharm. Sci. 2001, 14, 101-114.

(14) Boddé, H. E.; van der Brink, I.; Koerten, H. K.; de Hann, F. H. N. J. Controlled Release 1991, 15, 227-236.

(15) Bouwstra, J. A.; Gooris, G. S.; Salomons-De Vries, M. A.; van der Spek, J. A.; Bras, W. Int. J. Pharm. 1992, 84, 205-216.

(16) Silva, C. L.; Toppgaard, D.; Kocherbitov, V.; Pais, A. A. C. C.; Sousa, J. J. S.; Sparr, E. Manuscript in preparation. $73-78$
(18) Ulmius, J.; Wennerström, H.; Lindblom, B.; Arvidson, G. Biochemistry 1977, 16, 5742-5745.

(19) Shah, J.; Atienza, J. M.; Rawlings, A. V.; Shipley, G. G. J. Lipid Res. 1995, 36, 1945-1955.

(20) Gay, C. L.; Guy, R. H.; Golden, G. M.; Mak, V. H. W.; Francoeur, M. L. J. Invest. Dermatol. 1994, 103, 233-239.

(21) Sparr, E.; Wennerström, H. Biophys. J. 2001, 81, 10141028

(22) Rawlings, A. V.; Scott, I. R.; Harding, C. R.; Bowser, P. A. J. Invest. Dermatol. 1994, 103, 731-740.

(23) Nakagawa, N.; Sakai, S.; Matsumoto, M.; Yamada, K.; Nagano, M.; Yuki, T.; Sumida, Y.; Uchiwa, H. J. Invest. Dermatol. 2004, 122, 755763.

(24) Tabachnick, J.; LaBadie, J. H. J. Invest. Dermatol. 1970, 54, 2431

(25) Rawlings, A. V.; Harding, C. R. Dermatol. Ther. 2004, 17, 4348

(26) Hara, M.; Verkman, A. S. Proc. Natl. Acad. Sci. U.S.A. 2003, 100 $7360-7365$

(27) Marstein, S.; Jellum, E.; Eldjarn, L. Clin. Chim. Acta 1973, 49, $389-395$.

(28) Sybert, V. P.; Dale, B. A.; Holbrook, K. A. J. Invest. Dermatol. 1985, 84, 191-194.

(29) Wellner, K.; Fiedler, G.; Wohlrab, W. Z. Hautkrankh. 1992, 67, $648-650$.

(30) Lodén, M. J. Eur. Acad. Dermatol. Venereol. 2005, 19, 672-688.

(31) Rudolph, R.; Kownatzki, E. Contact Dermatitis 2004, 50, 354358.

(32) Greenspan, L. J. Res. Natl. Bur. Stand., Sect. A 1977, 81A, 89-

96.

(33) Nyqvist, H. Int. J. Pharm. Technol. Prod. Manuf. 1983, 4, 47-48.

(34) Janiak, M. J.; Small, D. M.; Shipley, G. G. J. Biol. Chem. 1979, $254,6068-6078$.

(35) Smith, G. S.; Sirota, E. B.; Safinya, C. R.; Plano, R. J.; Clark, N. A. J. Chem. Phys. 1990, 92, 4519-4529.

(36) LeNeveu, D. M.; Rand, R. P.; Parsegian, V. A. Nature 1976, 259 601-603.

(37) Feng, Y.; Yu, Z. W.; Quinn, P. J. Chem. Phys. Lipids 2002, 114, $149-157$.

(38) Yeagle, P. L.; Sen, A. Biochemistry 1986, 25, 7518-7522.

(39) Sanderson, P. W.; Lis, L. J.; Quinn, P. J.; Williams, W. P. Biochim. Biophys. Acta 1991, 1067, 43-50.

(40) Crowe, L. M.; Crowe, J. H. Biochim. Biophys. Acta 1991, 1064, 267-274.

(41) Rudolph, A. S.; Goins, B. Biochim. Biophys. Acta 1991, 1066, 90

(42) Guldbrand, L.; Jönsson, B.; Wennerström, H. J. Colloid Interface Sci. 1982, 89, 532-541.

(43) Cevc, G. Phospholipids Handbook; Marcel Dekker: New York, 1993.

(44) Gabriella-Madelmont, C.; Perron, R. J. Colloid Interface Sci. 1983 $95,471-482$.

(45) Markova, N.; Sparr, E.; Wadsö, L.; Wennerström, H. J. Phys. Chem. B 2000, 104, 8053-8060.

(46) Gucker, F. T.; Pickard, H. B. J. Am. Chem. Soc. 1940, 62, 14641472.

(47) Grollman, A. J. Gen. Physiol. 1931, 14, 661-683.

(48) Scatchard, G.; Hamer, W. J.; Wood, S. E. J. Am. Chem. Soc. 1938, $60,3061-3070$

(49) Oliver, A. E.; Crowe, L. M.; Crowe, J. H. Seed Sci. Res. 1998, 8 , 211-221.

(50) Crowe, J. H.; Crowe, L. M.; Chapman, D. Science 1984, 223, 701703.

(51) Walter, A.; Kuehl, G.; Barnes, K.; VanderWaerdt, G. Biochim. Biophys. Acta, Biomembr. 2000, 1508, 20-33.

(52) Mukerjee, P.; Ray, A. J. Phys. Chem. 1963, 67, 190-196.

(53) Froebe, C. L.; Simion, F. A.; Ohlmeyer, H.; Rhein, L. D.; Mattai, J.; Cagan, R. H.; Friberg, S. E. J. Soc. Cosmet. Chem. 1990, 41, 5165

(54) Mattai, J.; Froebe, C. L.; Rhein, L. D.; Simion, F. A.; Ohlmeyer, H.; Su, D. T.; Friberg, S. E. J. Soc. Cosmet. Chem. 1993, 44, 89100 . 